\title{
Effects of High-Activity and High-Energy Play vs. Low-Activity and Low-Energy Play on Hong Kong Preschool Boys' and Girls' Creativity
}

\section{Keang Ieng Peggy Vong1, Doris Pui Wah Cheng'2, Hui Ping Wu ${ }^{3}$, Chester Chun Seng Kam¹, Karen Liu 4}

${ }^{1}$ University of Macau, Macau, China

${ }^{2}$ Tung Wah College, Hong Kong, China

${ }^{3}$ Fujian Normal University, Fuzhou, China

${ }^{4}$ Indiana State University, Terre Haute, IN, USA

Email: peggykiv@umac.mo

How to cite this paper: Vong, K. I. P., Cheng, D. P. W., Wu, H. P., Kam, C. C. S. \& Liu, K. (2017). Effects of High-Activity and High-Energy Play vs. Low-Activity and Low-Energy Play on Hong Kong Preschool Boys' and Girls' Creativity. Creative Education, 8, 2377-2392.

https://doi.org/10.4236/ce.2017.815162

Received: October 13, 2017

Accepted: December 3, 2017

Published: December 6, 2017

Copyright (c) 2017 by authors and Scientific Research Publishing Inc. This work is licensed under the Creative Commons Attribution International License (CC BY 4.0).

http://creativecommons.org/licenses/by/4.0/

\begin{abstract}
This study examines the relationship between two types of preschool programmes and children's creativity performance in Hong Kong context using Torrance TCAM measurement. A pretest-intervention-posttest design was adopted. Post-test results showed that children schooled in the play-oriented preschool, and those in the academic-oriented preschool both improved in creativity scores after inquisitive-play or informed-play were added. Post-test results also showed different gender effects. Finally, the dimensions of TCAM which drive the boys' and girls' gain in creativity scores were identified.
\end{abstract}

\section{Keywords}

Creativity, Inquisitive-Play, Informed-Play, Academic-Oriented Preschool, Play-Oriented Preschool

\section{Introduction}

Creativity has been seen as a much needed human capacity for our future generations living in a fast changing, unpredictable and competitive world for a few decades (Duffy, 1998; Craft, 2002; Shaheen, 2010). The emergent competitiveness amongst nations has brought the past teaching objectives of some societies to revision. The importance of fostering creativity in children is evident in government reports, documents, and literature of both Western and Asian societies, such as The NACCCE Report (1999) in the U.K.; The Desired Out- 
comes of Education of the Ministry of Education in Singapore (1998); The Learning to Learn: The Way Forward in Curriculum Development in the Hong Kong Special Administrative Region (Curriculum Development Council, 2001; Chien, Wang \& Chen, 2001; Runco, 2007). But the "what" of learning does not mean much without understanding the "how" of learning, thus highlighting the importance of both curriculum designs and pedagogical strategies involved (Anning \& Edwards, 1999).

Play is generally known in the West as an important means to stimulate various aspects of children's development and creative ideas (Maynard, 1973; Craft, 2002; Wood \& Attfield, 2005; Pramling-Samuelsson \& Johansson, 2006), manifestations of cultural, personal, and everyday life experiences (UNESCO, 1980; European Commission, 2009). In Hong Kong, the recent emphasis on promoting Hong Kong children's creativity encourages preschools to promote creative minds through curriculum reform while highlighting the benefits of play to children's cognitive development (The Curriculum Development Council, 2006). Thereafter, the importance of play has since then been repeatedly reiterated in the Kindergarten Education Curriculum Guide (Education Bureau, 2017). Nonetheless, most of the preschool programmes in Hong Kong are still academic-focused while teachers use play as a tool for teaching instead of implementing a child-centred, play-based practice as suggested in the Curriculum Guide (Pearson \& Rao, 2006; Cheng, 2010; Cheng, Reunamo, Cooper, Liu, \& Vong, 2015). There is an obvious gap between the rhetoric of play and play at practice (Cheng, 2001).

Some scholars relate the challenge to social issues such as Chinese parents cannot be easily convinced of children's knowledge accumulation in play-based practices (Pearson \& Rao, 2006; Fung \& Cheng, 2012). Moreover, Rao, Ng, \& Pearson (2010) reckoned that the emphasis on instructional pedagogy, which is a distinct feature of Chinese approach to teaching and learning, still prevails in Hong Kong preschools. Embedded in a mix of Chinese and Western cultures, preschool education in Hong Kong has become a junction of disparate curricula and pedagogies, consequently a distinct Hong Kong Chinese Early Childhood Pedagogy has been formed (Rao, Ng, \& Pearson, 2010). Similar situation has been observed in more recent studies, showing parents' concerns about child-initiated and play-oriented curriculum, especially parents who have less social resources and social capital (Choi, 2016).

Another social issue, less mentioned in Hong Kong when curriculum and pedagogy reform is exercised, is related to young children's gender differences in learning and other aspects of development. Gender differences in young children's academic performance across schooling stages have been found in the U.K. (Safford, O'Sullivan, \& Barrs, 2004; Lau \& Cheung (2006) reported that Hong Kong primary and secondary school girls' gain in creativity could be due to girl-friendly schooling environments. The fact that gender issues at young age have been overlooked is in itself an educational and social issue. To our knowledge, no direct comparison of the play elements adopted by the two types of 
programme (i.e. academic-oriented and play-based) in response to the government's call to promote creativity in young children and in relation to boys' and girls' creativity performance, has been conducted. This study aims to fill this gap empirically using TCAM, a Torrance creativity testing instrument.

\section{Literature Review}

Many believe that just like other abilities, creativity is a human capacity which can be fostered in young children (Maynard, 1973; Craft, 2002; Duffy, 1998). However, what creativity means to people in a particular society or culture may vary (Zigler \& Bishop-Josef, 2004; Lau, Hui, \& Ng, 2009). Consequentially, the strategies each employs to foster creativity may differ (Wu \& Albanese, 2010).

Garaigordobil \& Berrueco (2011) mentioned various kinds of play that are practised in preschools to enrich children's creativity. While some kinds of play are part of the normal syllabus, others appear in the form of creative play training programmes which take place outside the normal syllabi. Garaigordobil \& Berrueco (2011) measured the effects of a play training programme for 5to 6-year-olds, which was administered outside the normal syllabi but took place weekly over a school year, and found increased performance level in creativity. Antonietti (2000) trained 5- to 7-year-olds creative analogical thinking and reported that children's analogical thinking and creativity were improved. We also know that diverse preschool programmes which originate from dissimilar cultures and consist of play elements and imagination at various levels have specific effects on children's creativity (Kirkham \& Kidd, 2015). The types of play stemmed from formal-education should not be neglected. In an earlier and small study, the impact of programmes from the same culture but with different theoretical foundation (e.g. discovery-based and formal-education programmes) yielded varied kinds of play (Johnson, Ershler, \& Bell, 1980). Taken together, these studies indicate that deliberate efforts to promote children's creativity can yield noticeable changes in children's thinking. More importantly, they show that play of various nature could also have effects on children's creativeness.

The socio-cultural aspects of play have also been recognised in Chinese societies and elsewhere. Vong (2013) delineated that there are different modes of play in preschool classrooms in China, ranging from teacher-directed games and activities, child-initiated free play in playground and corner play of different nature; hence suggesting the diverse and social phenomena embedded in play. Moreover, play models that relate cooperative-interaction play to creativity (Garaigordobil \& Berrueco, 2011), and the group dynamic created by collaborative games (Etelapelto \& Lahti, 2008; Sawyer, 1997), demonstrated the social synergy involved in play and creativity. While socio-dramatic play stimulates improvised ideas, games of various nature are also found to be beneficial to children's imagination and divergent thinking (Sawyer, 1997).

Furthermore, play in preschool settings is also tied to gender issues. Earlier 
research has revealed that energetic girls are more likely to arouse disciplinary concerns from teachers than boys (Chick, Heilman-Houser, \& Hunter, 2002), revealing the social expectation for girls to be quiet and calm. In Asian cultures, there are certain expectations of gender-appropriate behaviours and achievement in that girls are supposed to be submissive, tolerant, and calm, while boys should be bold, active, and expressive (Ali, Krantz, Gul, Asad, Johansson, \& Mogren, 2011). Chen \& Rao (2012) found that teachers interacted noticeably more with boys than with girls and suggested that a traditional gender view is still being manifested in Chinese preschool classrooms in Hong Kong. In terms of cognitive style, Lewis \& Houtz (1986) showed that some creative thinking tests reveal boys' creative ideas which led to their production of mechanical toys, while those of girls had a daily life orientation, again suggesting that girls' and boys' cognitive thinking are nurtured according to gender roles. Nevertheless, Baer \& Kaufman (2006) argued that gender differences in creativity lack consistency. Garaigordobil \& Berrueco (2011) also reported that in young children's creativity studies, gender-related results seem to be rather mixed. It appears that the gender issues in preschools need to be further scruntinised.

\section{The Hong Kong scenario: hindrances and promotion of creativity}

One possible hindrance of Hong Kong children's creativeness has been associated with their schooling experiences. Wong (2008) pointed out that the undesirable creative level of Hong Kong children could be attributed to both curriculum design and teachers' pedagogical strategies that children experience. A cramped curriculum and a serious lack of opportunities to explore and experience, to provoke divergent thinking and new ideas, to interact with physical materials and space, and to explore and express themselves freely, were some of the reasons provided by the various stakeholders of preschool education in Hong Kong (Wong, 2008). In particular, freedom for exploration (Collado, 1999, in Wong, 2008) and chances for improvised expression of ideas (Sawyer, 1997) are beneficial for creativity, yet lacking in Hong Kong children's schooling experiences. Meanwhile, children's creativity level is believed to be associated with teachers' competence. Research found that Hong Kong preschool teachers lack creative pedagogies to promote learners' creative ideas (Forrester \& Hui, 2007; Wong, 2008). Furthermore, Wong (2008) reported that teachers strongly associated art, music and self-initiated physical activities with creativity, which they were not particularly good at. On the other hand, these domains of learning were not really the core ones in most Hong Kong preschools' curricula. As Csikzentmihalyi's System Theory argues, in the teaching and learning scenarios in preschool education, the experts in the system are the teachers in the field who could curtail or boost children's creativity via the pedagogies they adopt (Forrester \& Hui, 2007). More recently, Chien \& Hui (2010) also suggested that kindergarten teachers' perception of creativity is linked to their creative teaching and children's creative learning.

As mentioned above, many preschool curriculain Hong Kong still emphasise children's academic achievements such as vocabulary and writing in languages 
(Chinese and English), and mathematics. It appears that most kindergarten curricula and pedagogies have been designed and equipped to cater for academic outcomes, rather than "creativity-friendly" or facilitating play activities, such as opportunities to explore, imagine, and apply everyday experiences through play. Though the Hong Kong government has been advocating play as a means of promoting creativity in early childhood education, deliberate effort and contextual strategies are needed for transformations in curriculum and pedagogy to take place.

\section{The present study}

This study aimed to tap on preschool children's creativity performance resulting from the changes in preschool curriculum designs and teaching approaches so as to promote children's creativity in Hong Kong. Two types of curriculum and pedagogies were intervened, namely, an academic-oriented programme which emphasised children's learning outcomes with reading, writing, and arithmetic exercises and offered little play opportunities in the curriculum, hence called a $3 \mathrm{R}$ programme (Cheng et al., 2015); and a relatively child-centred programme which scheduled one day of games designed by teachers and was geared towards promoting children's creativity, communication, and collaboration, thus called a $3 \mathrm{C}$ programme (Cheng et al., 2015). Characteristics of the two programmes prior to intervention was introduced by this study are summarised in Table 1.

The research questions of this study include: 1) Is there any difference in the creativity level of children schooled in a child-centred and play-oriented programme (a 3C programme), and those in the teacher-directed and academic-oriented (a $3 \mathrm{R}$ programme) after selected play elements have been added to the programmes? i.e. Is there intervention effects; 2) Is there gender effect in the

Table 1. Characteristics of the two programmes prior to intervention as observed by researchers.

\begin{tabular}{|c|c|c|}
\hline Major Differences in & 3R Programme & 3C Programme \\
\hline Goal and objectives & Promote moral and academic achievement & $\begin{array}{l}\text { Promote children's creativity, collaboration } \\
\text { and communication }\end{array}$ \\
\hline $\begin{array}{l}\text { Curriculum design } \\
\text { and pedagogies }\end{array}$ & $\begin{array}{l}\text { - Emphasise English, arithmetic, reading and } \\
\text { writing; } \\
\text { - } \text { Adopt commercial teaching kits fully; } \\
\text { - Contents follow teaching materials from local } \\
\text { publishers; } \\
\text { - } \text { Teacher-directed discussions and peer } \\
\text { participation }\end{array}$ & $\begin{array}{l}\text { - Rather balanced, but art work was often displayed to } \\
\text { show children's creative ideas and self-expression; } \\
\text { - } \text { Appropriately use teaching kits; } \\
\text { - Make attempts to innovate curriculum; } \\
\text { - } \quad \text { Learning activities are linked to children's day to day life; } \\
\text { - Opportunities to collaborate with peers }\end{array}$ \\
\hline Teacher's role & $\begin{array}{l}\text { Make sure all the prescribed learning } \\
\text { objectives are achieved }\end{array}$ & $\begin{array}{l}\text { Based on their understanding of children's needs and } \\
\text { abilities, design games and other activities to facilitate the } 3 \mathrm{Cs}\end{array}$ \\
\hline $\begin{array}{c}\text { Professional } \\
\text { development opportunities }\end{array}$ & $\begin{array}{l}\text { Peer observation amongst teachers } \\
\text { as part of the in-house training }\end{array}$ & $\begin{array}{l}\text { Seminars and workshops about the } 3 \mathrm{C} \text { concepts } \\
\text { were provided as in-house professional training }\end{array}$ \\
\hline Learning Environment & No learning corners were set up & $\begin{array}{l}\text { Learning corners were set up in classrooms } \\
\text { to facilitate active learning experiences }\end{array}$ \\
\hline $\begin{array}{l}\text { Play-related activities } \\
\text { before intervention }\end{array}$ & $\begin{array}{l}\text { After school boys scout and } \\
\text { girls scout activities }\end{array}$ & $\begin{array}{l}\text { Weekly Game Day with activities } \\
\text { designed by teachers }\end{array}$ \\
\hline
\end{tabular}

Source: Observation field notes of the researchers. 
two types of programme after adding play elements to the programmes? 3) In what ways do children schooled in the $3 \mathrm{C}$ programme, and those in the $3 \mathrm{R}$ programme differ in scores amongst the three dimensions of creativity: fluency, imagination, originality?

\section{Research design, procedures and statistical analyses}

The study employed a pre-test intervention post-test design. A total of 59 preschoolers aged 4 to 5 years old participated in this study. By adopting Patton's (1990) purposive sampling, two preschools were recruited based on their performance reported in the government's quality assurance documents (Education Bureau, 2006/07). There were 30 children (15 boys and 15 girls) from 3C programme and 30 children ( 17 boys and 13 girls) from $3 \mathrm{R}$ programme invited to take part in the TCAM tasks. One girl of the $3 \mathrm{R}$ programme did not finish all the four TCAM tasks so her score was not included in the data set. Parents' consent was obtained through the head teachers and teachers of the two programmes. The chosen sampling method allows for making comparisons of data collected from different types of preschool programme in Hong Kong, i.e. teacher-directed and academic-oriented vs. child-centred and play-oriented (Cheng et al., 2015). Classroom teaching and off-lesson time or after-school activities were observed and video-recorded to facilitate further understanding of the programmes. All children were tested on creativity performance using TCAM, before and after "new" play elements were introduced and implemented during a six-month period.

\section{Instrument}

The Taiwan version of Torrance's (1981) research tool on Thinking Creatively in Action and Movement (TCAM), which taps on the three dimensions of children's fluency, imagination, originality, was administered to measure children's creativity. The Taiwan version (Chang, 2006) has been used on Taiwan preschool children who share the Chinese culture with their counterparts in Hong Kong. Before administering the instrument, the wording of the instructions was presented to two local preschool teachers in Cantonese (i.e. the dialect spoken in Hong Kong), who considered the wording as appropriate for use in Cantonese speaking preschools. This instrument requires young children to act out their ideas through movement and action instead of using verbal expressions, which makes it suitable for 3- to 8-year-old. As reported by Chang (2006), the instrument was tested for reliability and construct validity on fluency, imagination and originality and proved satisfactory. The TCAM instrument contains four tasks:

- How many ways they can think of to move from one point to the opposite point, each marked by colour blocks on the floor;

- What kinds of movement they can demonstrate if they were something else (e.g. if they were a fish, and if the fish were swimming in a stream or pond);

- What are the ways they can think of to put used and unwanted paper cups into a garbage can; 
- What could paper cups be used for besides drinking water or juices.

All the scores are assigned in accordance with a template of graded movements or actions obtained from the 561 sampled children (Chang, 2006). Activities 1, 3 and 4 are for measuring children's fluency and originality. The total number of points for fluency equals to the total number of responses given. For originality, each movement or action is given 0 - 3 points. Activity 2 measures imagination, and each response is given 1, 2, 3, 4 or 5 points.

\section{Procedures and Intervention}

During a six-month period, the 3C programme adopted an integrative inquisitive-play approach. There were field trips (collecting materials and information) and in-class teacher-guided discussions which involved expressing of ideas, questioning of ideas, testing of ideas, role playing, designing and setting up the classroom environment according to the topics of children's interests. The nature of these play types and elements which generated high-activity and high-energy levels in the learning environment would, in general, be considered by the Hong Kong education bureau as creativity-friendly or facilitating. As for the 3R programme, off school time activities (i.e. either during recess time or before or after school) such as Chinese lion dance and desk-top games popular amongst Hong Kong children, such as chess and card games, were added to the programme. These play opportunities at the 3R programme signify a kind of "informed-play" in the sense that the baby lion dance involved instructions on certain movements from teachers while imagination of the liveliness and spirit of a baby lion was left with the children. Likewise, as in all kinds of chess and card games, there are certain rules to be followed as well as opportunities to think quietly and strategically. Meanwhile, children can also invent new ways to play the games, which are up to the children. Nonetheless, the "informed-play" added by the $3 \mathrm{R}$ programme are of relatively low-activity and low-energy levels.

We hypothesised that: 1) increased play opportunities can improve these Hong Kong children's creativity; 2) high-activity and high-energy play experiences adopted by $3 \mathrm{C}$ programme will generate higher TCAM creativity scores than the informed-play in both girls and boys; 3 ) there is no difference in terms of post-test improvement scores amongst the three dimensions of creativity: fluency, originality, imagination.

\section{Statistical Analysis}

The pre-test and post-test results of the two programmes were compared for differences in terms of fluency, imagination, originality, in order to examine the intervention effects. The TCAM scores of the $3 \mathrm{C}$ children and their counterparts at the $3 \mathrm{R}$ programme were also compared so as to investigate the effects of different types of play that these two groups experienced. Then the scores yielded by boys and girls from the two programmes were used as testimony of gender and programme effects.

As a common constraint in applied research, we could not conduct random assignment. To address this limitation, we measured group differences in crea- 
tivity before intervention and used this pre-test as a baseline when examining children's improvement in their creativity scores at post-intervention. Our subsequent analyses thus used the improvement scores between pre-intervention and post-intervention as the outcome variable.

As the first step in our analyses, we examined whether the improvement scores between pre-test and post-test for each gender and programme were statistically significant. This analysis will provide us with a rough idea regarding the efficacy of each programme for children of each gender. With two genders and two programme types, we conducted four separate t-tests. Afterwards, we supplemented this analysis with an overall ANOVA analysis, in order to answer the question of which group (i.e. which gender under which programme) benefits the most and which benefits the least from the two programmes. We thus examined the possible interaction between programme type (3C vs. 3R) and gender (boys vs. girls) on children's creativity improvement at the end of the programme. For all of the aforementioned analyses, we looked at not only the significant level of an analysis but also the effect size (operationalised as percentage of improvement over time, and Cohen's d), due to our small sample size as common in intervention research (less than 20 participants on average in each cell). In addition, methodologists have warned against relying on significance level exclusively on concluding study results (e.g. Kirk, 1996). We arbitrarily pre-defined a $30 \%$ improvement in participants' creativity scores as a substantial improvement (as most programme evaluation researchers would probably agree with this standard as indicator of programme effectiveness). Cohen's $d$ is usually interpreted as the magnitude of score improvement in terms of standard deviation. According to the common guideline for Cohen's $d$, the value of 0.8 or above is considered a large effect size while the value of 0.5 is considered a medium effect size and 0.2 is interpreted as a small effect (Cohen, 1988).

Given that the focus of the current paper is on children's overall creativity, we averaged the three dimensions of creativity (i.e. fluency, originality, and imagination) and employed this overall score in our major statistical analyses. We realised, however, that some researchers have advocated the use of component/dimension scores of creativity instead of an overall index (Garaigordobil \& Berrueco, 2011). Therefore, we also report the results with the component scores at the end. This final analysis will aid us to understand which component(s) of creativity best accounts for the overall increase in creativity in our children.

We have considered using repeated measures ANOVA with both pre-test and post-test scores as outcome variables but the results were extremely difficult to interpret due to different baseline creativity level among our groups at pre-test. Our suggested plan here makes the most intuitive sense for readers to understand our results, because the use of improvement scores (post-test scores minus pre-test scores) is readily interpretable. In contrast, repeated measures use raw scores, making post-test scores difficult to interpret. All analyses were performed using SPSS statistical software, version 21. 


\section{Findings}

We first tested programme and gender differences in creativity scores at the pre-intervention level. Children under programme 3C were found to have higher pre-intervention creativity score than those under programme $3 \mathrm{R}\left(M_{3 C}\right.$ vs. $M_{3 R}=20.52$ vs. 11.76$), t=2.50, p=0.02$. However, no gender difference in pre-intervention creativity was found ( $M_{b o y}$ vs. $M_{\text {girl }}=18.27$ vs. 18.53 ), $t=1.30, p$ $=0.20$. The programme $\times$ gender interaction was also non-significant, $F=0.06$, $p=0.81$. The descriptive statistics of the pre-test and post-test of creativity score are presented in Table 2. As all subsequent analysis employed the improvement score as the dependent variable, pre-intervention differences alone unlikely explain our results.

We then examined under which programme children showed the largest improvement in their creativity scores at post-test. Therefore, we compared the creativity improvement scores for each combination of gender (boys vs. girls) and programme (3C vs. $3 \mathrm{R}$ ). Figure 1 showed score improvement at the end of the programme. Girls under the programme 3R showed a statistically significant

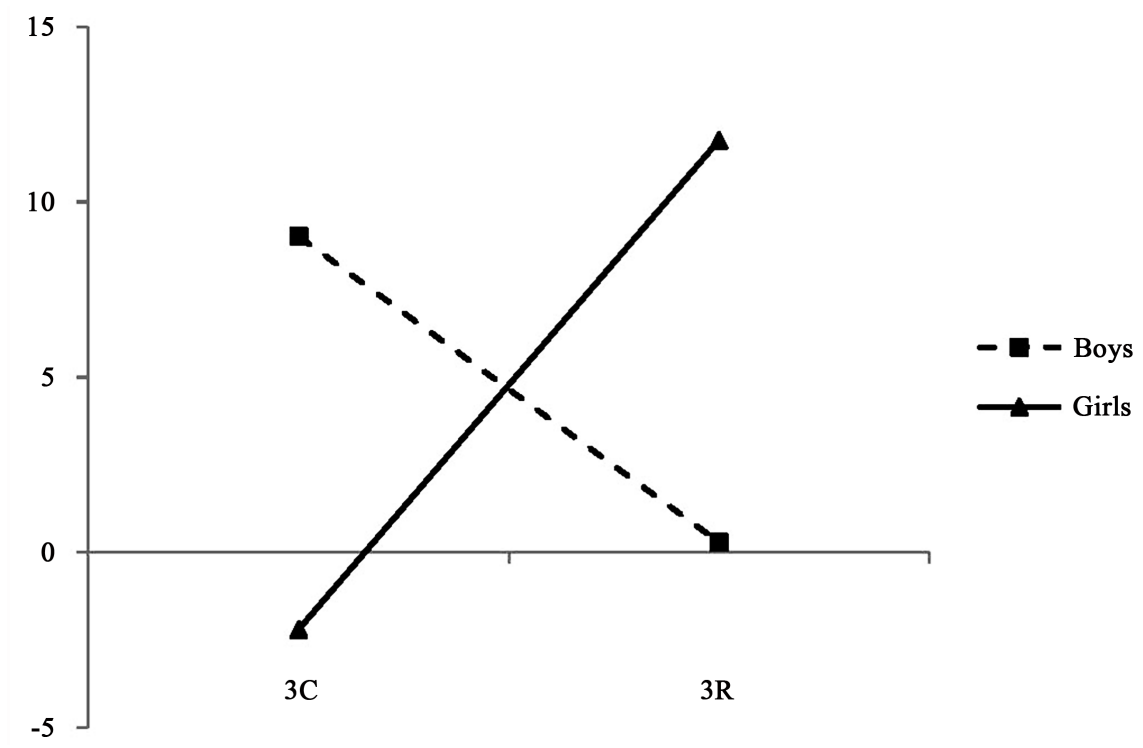

Figure 1. The effect of programme type and gender on overall creativity improvement score.

Table 2. Means (standard deviations) of pre-test, post-test score and improvement.

\begin{tabular}{ccccccc}
\hline & \multicolumn{3}{c}{$3 \mathrm{C}$} & & \multicolumn{3}{c}{$3 \mathrm{R}$} \\
\cline { 2 - 7 } & Total & Boy & Girl & Total & Boy & Girl \\
\hline \multirow{2}{*}{ Pre-test } & 20.52 & 23.78 & 17.27 & 11.86 & 13.69 & 8.88 \\
& $(17.28)$ & $(15.28)$ & $(19.03)$ & $(8.58)$ & $(9.60)$ & $(5.81)$ \\
& 23.93 & 32.80 & 15.07 & 16.51 & 13.98 & 20.64 \\
Post-test & $(20.58)$ & $24.68)$ & $(9.96)$ & $(13.20)$ & $(9.76)$ & $(17.19)$ \\
& 3.42 & 9.02 & -2.20 & 4.64 & 0.30 & 11.76 \\
Improvement & $(21.16)$ & $(22.44)$ & $(18.89)$ & $(12.72)$ & $(10.91)$ & $(12.68)$ \\
& & & & & & \\
\hline
\end{tabular}


improvement (improvement $=+11.76$ or $132.4 \%$ increase, Cohen's $d=0.93$ ), $t=$ 3.07, $p=0.01$. The effect size for score increase is considered large. In addition, it is noticeable in the figure that boys under programme $3 \mathrm{C}$ showed quite substantial increase in their creativity score (improvement $=+9.02$ or $37.9 \%$ increase, Cohen's $d=0.40$ ), although the increase has not reached the traditional level of significance, $t=1.56, p=0.14$. The effect size of the score increase was about $40 \%$ of a standard deviation, close to a medium effect size. Looking at the absolute score improvement, however, we found that the magnitude for girls under programme $3 \mathrm{R}$ were close to the magnitude for boys under programme $3 \mathrm{C}(+11.76$ vs. +9.02$)$, and the magnitude of score improvement was not statistically different between both groups, $t=0.36, p=0.72$. This result suggested that both groups were able to be equally benefited from the respective programmes (in terms of the absolute score improvement). In comparison to the two groups previously mentioned, boys under programme $3 \mathrm{R}$, as well as girls under programme 3C, did not show statistically significant improvement: the effect size was also not substantial in both groups (boys under 3R: improvement $=+0.30$ or $2.2 \%$ increase, Cohen's $d=0.03$; girls under $3 \mathrm{C}$ : improvement $=$ -2.20 or $12.7 \%$ decrease, Cohen's $d=0.12$ ), $t \mathrm{~s}<0.45$, $p s>0.66$. These post-test results preliminarily suggested that different programmes and the added play types benefit students of different genders: girls were significantly improved under programme $3 \mathrm{R}$, and boys showed a noticeable trend of improvement, albeit non-significantly, under programme 3C. The absolute increase in creativity score is actually similar across both groups.

To further understand how gender moderates the benefits of programme types, we attempted to conduct a 2 (programme: $3 \mathrm{C}$ versus $3 \mathrm{R}$ ) $\times 2$ (gender: boys versus girls) ANOVA analysis, with improvement score (the difference between post-test scores and pre-test scores) as the outcome variable. Results showed no main effect but only significant programme $\times$ gender interaction effect on the creativity improvement scores (Figure 1 ), $F=6.45, p=0.01$. Our ANOVA results were consistent with our earlier results with the $t$-tests. For girls, those under 3R shows significantly higher improvement scores than those under 3C, $M \mathrm{~s}$ $=11.76$ vs. $-2.20, F=4.34, p=0.04$, Cohen's $d=0.84$. For boys, those under $3 \mathrm{C}$ shows a trend of higher improvement score than those under $3 \mathrm{R}$, although the improvement has not reached the traditional level of significance despite the apparently medium effect size, $M s=+9.02$ vs. $+0.30, F=2.19, p=0.15$, Cohen's $d=0.51$. Another way to study the significant interaction was to look at gender differences within each programme. For programme 3C, boys showed a trend of higher creativity improvement scores than girls, $M s=9.02$ vs. $-2.20, F=3.31, p$ $=0.07$, Cohen's $d=0.54$. For programme 3R, in contrast, girls showed a trend of higher creativity improvement scores than boys, $M s=11.76$ vs. $0.30, F=3.15, p$ $=0.08$, Cohen's $d=0.99$. Therefore, these results were consistent with our previous $t$-test results that students of different gender benefited from different creativity programmes. 
Finally, we examined what drove the improvement of the overall creativity scores for boys under $3 \mathrm{C}$ and for girls under $3 \mathrm{R}$. For girls under programme $3 \mathrm{R}$, the improvement was due to all three components, fluency (improvement = +13.45 or $174.1 \%$ increase, Cohen's $d=0.88, t=2.92, p=0.02$ ), originality (improvement $=+18.55$ or $272.0 \%$ increase, Cohen's $d=0.88, t=2.93, p=0.02$ ), and imagination (improvement $=+3.27$ or $27.1 \%$ increase, Cohen's $d=0.98, t=$ $3.241, p=0.01$ ). For boys under programme $3 \mathrm{C}$, the improvement was probably due to the components fluency (improvement $=+11.20$ or $46.8 \%$ increase, Cohen's $d=0.50, t=1.94, p=0.07$ ), but not due to originality (improvement $=$ +15.80 or $52.1 \%$ increase, Cohen's $d=0.30, t=1.47, p=0.17$ ) or imagination (improvement $=+0.07$ or $0.4 \%$ increase, Cohen's $d=0.01, t=0.05, p=0.96$ ).

\section{Discussion and Implications}

While the scale of this research is limited and generalisation of the results should be cautious, this study found effects of different types of play on children's creativity, as well as gender effects. We believe that the results raise interesting and complex implications for early childhood educators.

\subsection{Appropriated Play Opportunities and Children's Creativity}

Our first research question asks whether there is any difference in the creativity level of children schooled in the $3 \mathrm{C}$ and $3 \mathrm{R}$ programmes after increasing play elements and opportunities in the two programmes. We found that after strengthening the relatively child-centred 3C programme with inquisitive-play, which is of high-activity and high-energy level, and adding informed-play to the $3 \mathrm{R}$ programme, which are of relatively low-activity and low-energy level, improvement in creativity was found in children from both programmes, even though there were some variations in improvement sizes. Hence, our first hypothesis that increased play opportunities can improve these Hong Kong children's creativity is confirmed. At the least, such result supports previous research that even short period of intervention can bring improvement to children's creativity level (Garaigordobil \& Berrueco, 2011). Moreover, the result supports previous finding in that questioning, exploration (Collado, 1999, cited in Wong, 2008), and chances for improvised expression of ideas (Sawyer, 1997) improved children's creativity. Meanwhile, it is evidenced that deliberate and fine-tuning effort to improve children's creativity, such as increasing play time and play elements during off-lesson hours, as exemplified by the $3 \mathrm{R}$ programme, is useful in enhancing children's creative thinking. All these deliberate efforts and the elevated creativity levels echo a point made by Wood (2007) that appropriate pedagogies to employ play in preschool education should be considered.

\subsection{Activity and Energy Levels of Play Reflect Gender Issues at Young Age}

We also asked whether there are gender effects in the two types of programme after adding play elements. Previous research have found mixed results (Baer \& 
Kaufman, 2006; Garaigordobil \& Berrueco, 2011). This research shows that boys are more sensitive to the added inquisitive-play opportunities than girls in terms of their improvement score at post-test, even though it was only marginally significant. Therefore, our hypothesis that the play elements adopted by $3 \mathrm{C}$ programme will generate higher TCAM creativity scores than the informed-play in boys and girls is only partly true. The added inquisitive-play opportunities provided $3 \mathrm{C}$ boys with greater freedom to move around physically, expressing their ideas, testing those ideas, and modifying their physical learning environment according to their hypotheses and experiments. As literature shows that boys learn better with more concrete sensory way and excel in that kind of learning environment (Safford, O'Sullivan, \& Barrs, 2004). The added inquisitive-play approach leads to high-activity and high-energy levels of play opportunities. It appears that the social expectations of boys to be active, bold, and expressive, are met by the play opportunities offered by an inquisitive-play approach, thus supporting the social roles identified previously (Ali et al., 2011). This argument is further supported by the fact that $3 \mathrm{R}$ boys did not benefit much in terms of gain in creativity scores from the informed-play added to the $3 R$ programme. During this kind of informed-play children have to follow certain steps prior to using their imagination and innovative ideas, and are low-activity and low-energy in nature. However, it challenges children's imagination and strategic thinking, rather than require them to be physically active, expressive, or explorative. Therefore, it seems that while informed-play requires patience, sometimes tolerance, calmness, and strategic thinking, informed-play also prompts creative thinking. Meanwhile, informed-play is complementary to the social expectation of girls in Asian cultures. Vong (2013) did not report the existence of informed-play. Even though this kind of informed-play added by the $3 \mathrm{R}$ programme has had an effect on girls' creativity, it is so common amongst children's play types that it might easily be neglected.

These findings are alarming for boys as most preschools in Hong Kong are $3 \mathrm{R}$-oriented, in which boys have little opportunities to be inquisitive and experiment with their ideas and senses, thus putting them in a disadvantaged position in terms of learning and creativity performance. Meanwhile, the significant improvement of $3 \mathrm{R}$ girls in terms of creativity scores at post-test might have implication on the kind of play, added to academic-oriented kindergarten, that benefit girls' creativity. As mentioned earlier, in the Chinese culture, girls are expected to be gentle, calm, and quiet. Previous argument stated that energetic girls are more likely to arouse disciplinary concerns from teachers than boys (Chick et al., 2002), thus encouraging boys but discouraging girls to be active physically. Such teachers' view might have been magnified in Chinese classrooms, and reflected in $3 \mathrm{R}$ girls' positive reactions to play that requires little self-expression and movements. This finding also echoes previous claim that there is traditional Chinese beliefs about the gender-specific roles of men and women in Hong Kong society (Rao, Ng, \& Pearson, 2010). According to the present study, these beliefs could have in fact existed in Hong Kong as early as 
preschool education. While Hong Kong government encourages free play and inquisitive-play in preschool programmes, girls are not benefiting as much from this mode of play as boys. Previous research has shown that girls' creativity can be enhanced once the programmes and learning environment are modified to favour their "inhibitions due to the cultural constraint demands" (Lau \& Cheung, 2006: 334). In terms of providing equal opportunities in education for both genders, these findings signify that gender-specific effects of different modes of play on these young Hong Kong children, and urge early childhood educators to pay attention to diversities as the adverse effects of the social expectations on boys and girls so as to maximise their learning potentials.

\subsection{Rethinking Creativity-Its Components and Contextual Factors}

This study shows the complexity of the notion of creativity as children in the $3 \mathrm{C}$ and $3 \mathrm{R}$ programmes differ in performance amongst the three dimensions or components of creativity: fluency, imagination, and originality. The concept of creativity developed by Torrance, and subsequently used to develop the TCAM and other instruments, argued that creativity is not a single ability but an aptitude that comprises of various dimensions (Torrance, 1981). We are intrigued to understanding whether programme intervention with different modes of play will promote certain dimensions and not others. Results showed that in the $3 \mathrm{C}$ programme, the improvement in scores was probably driven by the boys' fluency scores (improvement almost reached significant level), but not imagination nor originality scores. On the contrary, the improved scores of children in the $3 \mathrm{R}$ programme was due to the girls' overall performance, again, in all three components, and all three reached significant levels. In other words, the 3C boys' fluency improved after being exposed to the inquisitive-play in which expression and testing of ideas are encouraged. As defined by the TCAM instrument, fluency is the number of ideas generated within a certain time frame, i.e. the more ideas generated, the higher the score. The finding that $3 \mathrm{C}$ boys performed exceptionally better on this dimension might suggest that they benefited from the opportunity to generate ideas and test those ideas, while imagination and originality have not been encouraged as much. Since the sample size in this study is small, we are aware that the result cannot be generalised. In the post-modern era when creativity is a virtue which matters for personal success, this study shed light on the relationship between intervention and children's creativity while researchers can further unpack this kind of work.

\subsection{Limitations}

First of all, this study is based on a small sample in Hong Kong whereas across the city there are other play elements added into the academic-oriented Chinese preschools. As stated earlier in this article, the academic 3R programmes focus on reading, writing, and arithmatics, if children were assessed on language- and literacy-related creativity measurements, they might manifest creativity levels at very different nature, a future research direction to be considered. 


\section{References}

Ali, T. S., Krantz, G., Gul, R., Asad, N., Johansson, E., \& Mogren, I. (2011) Gender Roles and Their Influences on Life Prospects for Women in Urban Karachi, Pakistan: A Qualitative Study. Glob Health Action, 4, 7448.

Anning, A., \& Edwards, A. (1999) Promoting Children's Learning from Birth to Five. Buckingham: Open University Press.

Antonietti, A. (2000) Enhancing Creative Analogies in Primary School Children. North American Journal of Psychology, 2, 75-84.

Baer, J., \& Kaufman, J. C. (2006) Gender Differences in Creativity. Journal of Creative Behavior, 42, 75-105. https://doi.org/10.1002/j.2162-6057.2008.tb01289.x

Chang, S. H. (2006) TCAM-Thinking Creatively in Action and Movement-Manual. Taipei, TN: Psychological Publishing Co. Ltd. (In Chinese)

Chen, E. S. L., \& Rao, N. (2012) Classroom Processes of Gender Socialization in Four Chinese Kindergartens: A Contextual Account on the Teachers' Practices and Contributions. Journal of Communications Research, 5, 139-164.

Cheng, D. P. W. (2001). Difficulties of Hong Kong Teachers' Understanding and Implementation of 'Play' in the Curriculum. Teaching and Teacher Education, 17, 857-869. https://doi.org/10.1016/S0742-051X(01)00035-X

Cheng, D. P. W. (2010) Exploring the Tactfulness of Implementing Play in the Classroom: A Hong Kong Experience. Asia Pacific Journal of Teacher Education, 38, 69-82.

Cheng, D. P. W., Reunamo, J., Cooper, P., Liu, K. K. Y., \& Vong, K. I. P. (2015) Children's Agentive Orientations in Play Based and Academic Focused Preschools in Hong Kong. Early Child Development and Care, Special Issue: Early Childhood Pedagogy, 185, 1818-1844. https://doi.org/10.1080/13598660903474163

Chick, K. A., Heilman-Houser, R. A., \& Hunter, M. W. (2002) Theimpact of Child Care on Gender Role Development and Gender Stereotypes. Early Childhood Education Journal, 29, 149-154. https://doi.org/10.1023/A:1014528424032

Chien, C. Y., \& Hui, A. N. N. (2012). Creativity in early childhood education: Teachers' perceptions in three Chinese societies. Thinking Skills and Creativity, 5, 49-60.

Chien, C. Y., Wang, Y. Y., \& Chen, S. F. (2001). Creativity of Preschool Children: Formulation of Educational Policy. Taiwan: Ministry of Education (A Technical Report Submitted to Ministry of Education Project on White Paper on Creative Education: Establishing a Republic of Creativity) (In Chinese).

Choi, K. W. Y. (2016). On the Fast Track to a Head Start: A Visual Ethnographic Study of Parental Consumption of Children's Play and Learning Activities in Hong Kong. Childhood, 23, 123-139. https://doi.org/10.1177/0907568215586838

Cohen, J. (1988). Statistical Power Analysis for the Behavioral Sciences (2nd ed.). New Jersey: Lawrence Erlbaum.

Craft, A. (2002). Creativity and Early Years Education. London: Continnum.

Curriculum Development Council (2001). Learning to Learn: The Way Forward to Curriculum Development. Hong Kong: Government Printer.

Curriculum Development Council (2006). Guide to the Pre-Primary Curriculum. The Education Bureau HKSAR. Available at:

http://www.edb.gov.hk/attachment/en/edu-system/preprimary-kindergarten/overview/ pre-primaryguide-net_en_928.pdf (assessed 8 August 2017).

Duffy, B. (1998). Supporting Creativity and Imagination in the Early Years. Buckingham: Open University Press. 
Education Bureau (2006). Kindergartens Quality Assurance Inspection (QAI) Annual Report. Available at:

http://www.edb.gov.hk/attachment/en/sch-admin/sch-quality-assurance/reports/insp-a nnual-reports/06-07_inspection_annual_report_eng.pdf (assessed 1 November 2014).

Education Bureau (2017). Kindergarten Education Curriculum Guide-Tentative Final Version. Available at:

http://www.edb.gov.hk/attachment/tc/curriculum-development/major-level-of-edu/pre primary/kgecg2017_c.pdf (assessed 12 September 2017) (In Chinese).

Etelapelto, A., \& Lahti, J. (2008). Theresources and Obstacles of Creative Collaboration in a Long-Term Learning Community. Thinking Skills and Creativity, 3, 175-250.

European Commission (2009). Creativity and Innovation European Year. Available at: http://www.create2009.europa.eu/ (accessed 2 September 2017).

Forrester, V., \& Hui, A. (2007). Creativity in the Hong Kong Classroom: What Is the Contextual Practice? Thinking Skills and Creativity, 2, 30-38.

Fung, K. H. C., \& Cheng, P. W. D. (2012). Consensus or Dissensus? Stakeholders' Views on Learning through Play. Early Years: An International Journal of Research and Development, 32, 17-33. https://doi.org/10.1080/09575146.2011.599794

Garaigordobil, M., \& Berrueco, L. (2011). Effects of a Play Program on Creative Thinking of Preschool Children. The Spanish Journal of Psychology, 14, 608-618. https://doi.org/10.5209/rev_SJOP.2011.v14.n2.9

Johnson, J. E., Ershler, J., \& Bell, C. (1980). Play Behaviour in a Discovery-Based and a Formal-Education Preschool Program. Child Development, 51, 271-274.

Kirk, R. E. (1996). Practical Significance: A Concept Whose Time Has Come. Educational and Psychological Measurement, 56, 746-759. https://doi.org/10.1177/0013164496056005002

Kirkham, J., \& Kidd, E. (2015). The Effect of Steiner, Montessori, and National Curriculum Education upon Children's Pretence and Creativity. Journal of Creative Behavior, 51, 20-34.

Lau, S., \& Cheung, P. C. (2006). Developmental Trends of Creativity: What Twists of Turn Do Boys and Girls Take at Different Grades? Creativity Research Journal, 22, 329-336.

Lau, S., Hui, A. N. N., \& Ng, G. Y. C. (2009). Creativity: When East Meets West. Singapore: World Scientific.

Lewis, C. D., \& Houtz, J. C. (1986). Sex-Role Stereotyping and Young Children's Divergent Thinking. Psychological Reports, 59, 1027-1033.

https://doi.org/10.2466/pr0.1986.59.3.1027

Maynard, F. (1973). Guiding Your Child to a More Creative Life. New York, NY: Doubleday and Company Inc.

Ministry of Education (1998). Desired Outcomes of Education. Singapore. http://www.moe.gov.sg/education/desiredoutcome/

Patton, M. (1990). Qualitative Evaluation and Research Methods. Beverly Hills, CA: Sage.

Pearson, E., \& Rao, N. (2006). Early Childhood Education Policy Reform in Hong Kong: Challenges in Effecting Change in Practice. Childhood Education, 82, 363-369. https://doi.org/10.1080/00094056.2006.10522863

Pramling-Samuelsson, I., \& Johansson, E. (2006). Play and Learning-Inseparable Dimensions in Preschool Practice. Early Child Development and Care, 176, 47-65.

https://doi.org/10.1080/0300443042000302654

Rao, N., Ng, S. S. N., \& Pearson, E. (2010). Preschool Pedagogy: A Fusion of Traditional 
Chinese Beliefs and Contemporary Notions of Appropriate Practice. In C. K. K. Chan, \& N. Rao (Eds.), Revisiting the Chinese Learner: Changing Contexts, Changing Education. Hong Kong: The University of Hong Kong, Comparative Education Research Centre.

Runco, M. (2007). To Understand Is to Create: An Epistemological Perspective on Human Nature and Personal Creativity. In R. Richards (Ed.), Everyday Creativity and New Views of Human Nature: Psychological, Social, and Spiritual Perspectives (pp. 91-107). Washington DC: American Psychological Association.

https://doi.org/10.1037/11595-004

Safford, K., O'Sullivan, O., \& Barrs, M. (2004). Boys on the Margin: Promoting Boys' Literacy and Learning at Key Stage 2. London: Centre for Language in Primary Education.

Sawyer, R. K. (1997). Pretend Play as Improvisation: Conversation in the Preschool Classroom. New York, NY: Routledge.

Shaheen, R. (2010). Creativity and Education. Creative Education, 1, 166-169. https://doi.org/10.4236/ce.2010.13026

The National Advisory Committee on Creative and Cultural Education NACCCE (1999). All Our Future: Creativity, Culture and Education. London: DfES.

Torrance, E. P. (1981). Thinking Creatively in Action and Movement. Bensenville, IL: Scholastic Testing Service, Inc.

UNESCO (1980). The Child and Play: Theoretical Approaches and Teaching Applications. Educational Studies and Documents, New Series, No. 34.

Vong, K. I. P. (2013). Play-A Multi-Modal Manifestation in Kindergarten Education in China. Early Years: An International Journal of Research and Development, 32, 35-48.

Wong, V. W. Y. (2008). Promoting Children's Creativity through Teaching and Learning in Hong Kong. In A. Craft, T. Cremin, \& P. Burnard (Eds.), Creative Learning 3-11 and How We Document It (pp. 93-101). Stoke on Trent: Trentham Books.

Wood, E. (2007). New Directions in Play: Consensus or Collision. Education, 35, 309-320. https://doi.org/10.1080/03004270701602426

Wood, E., \& Attfield, J. (2005). Play, Learning and the Early Childhood Curriculum. London: PCP Limited.

Wu, J. J., \& Albanese, D. (2010). Asian Creativity, Chapter One: Creativity across Three Chinese Societies. Thinking Skills and Creativity, 5, 150-154. https://doi.org/10.1016/j.tsc.2010.10.002

Zigler, E. F., \& Bishop-Josef, S. J. (2006). The Cognitive Child versus the Whole Child: Learns from 40 Years of Head Start. In D. G. Singer, R. M. Golinkoff, \& K. Hirsh-Pasek (Eds.), How Play Motivates and Enhances Children's Cognitive and Social-Emotional Growth (pp. 15-35). New York, NY: Oxford University Press. https://doi.org/10.1093/acprof:oso/9780195304381.003.0002 